\title{
Factors associated with the development of aortic valve regurgitation over time after two different techniques of valve-sparing aortic root surgery
}

\author{
Thorsten Hanke, MD, ${ }^{\mathrm{a}, *}$ Efstratios I. Charitos, MD, ${ }^{\mathrm{a}, *}$ Ulrich Stierle, MD, ${ }^{\mathrm{a}, *}$ Derek Robinson, MA, MSc, DPhil, CStat, ${ }^{\mathrm{b}}$ \\ Armin Gorski, MD, ${ }^{\mathrm{c}}$ Hans-H. Sievers, MD, ${ }^{\mathrm{a}}$ and Martin Misfeld, MD, PhD ${ }^{\mathrm{a}}$
}

\begin{abstract}
Objective: Early results after aortic valve-sparing root reconstruction are excellent. Longer-term follow-up, especially with regard to aortic valve function, is required for further judgment of these techniques.
\end{abstract}

\begin{abstract}
Methods: Between July of 1993 and September of 2006, 108 consecutive patients (mean age $53.0 \pm 15.8$ years) underwent the Yacoub operation (group Y) and 83 patients underwent the David operation (group D). Innovative multilevel hierarchic modeling methods were used to analyze aortic regurgitation over time.
\end{abstract}

\begin{abstract}
Results: In general, aortic regurgitation increased with time in both groups. Factors associated with the development of a significant increase in aortic regurgitation were Marfan syndrome, concomitant cusp intervention, and preoperative aortic anulus dimension. In Marfan syndrome, the initial aortic regurgitation was higher in group Y versus group $\mathrm{D}(0.56$ aortic regurgitation vs 0.29 aortic regurgitation, $P=.049)$, whereas the mean annual progression rate of aortic regurgitation was marginally higher in group $\mathrm{Y}(0.132$ aortic regurgitation vs 0.075 aortic regurgitation, $P=.1)$. Concomitant cusp intervention was associated with a significant aortic regurgitation increase in both groups $(P<.0001)$. There was a trend that smaller preoperative aortic annulus diameters in group $\mathrm{D}$ and larger diameters in group $\mathrm{Y}$ were associated with increased aortic regurgitation over time.

Conclusion: In regard to aortic regurgitation grade over time, patients with Marfan syndrome and a large preoperative aortic annulus diameter were better treated with the reimplantation technique, whereas those with a smaller diameter were better treated with the remodeling technique. Concomitant free-edge plication of prolapsing cusps was disadvantageous in both groups. Considering these factors may serve to improve the aortic valve longevity after valve-sparing aortic root surgery.
\end{abstract}

Aortic valve-sparing operations to treat patients with aortic root pathologies are gaining interest because of the known limitations of alternative prosthetic valves. There are basically 2 types of aortic valve-sparing operations: the remodeling technique initially described by Yacoub $^{1}$ and the reimplantation technique introduced by David. ${ }^{2}$ Both surgical strategies support the wall of the aortic root to different extents. In addition to the Yacoub and David procedures, various modifications of these operations and modified vascular grafts have been introduced to improve functional characteristics of the aortic valve. ${ }^{3,4}$ These operations are theoretically appealing, and excellent early results may support more widespread application. However, none of these procedures have been able to meet the complexity of aortic

From the Clinic of Cardiac and Thoracic Vascular Surgery, University of Luebeck, ${ }^{\mathrm{a}}$ Luebeck, Germany; Department of Mathematics, School of Science and Technology, University of Sussex, ${ }^{\mathrm{b}}$ Brighton, United Kingdom; and Clinic for Thoracic, Heart, and Thoracic Vascular Surgery, ${ }^{\mathrm{c}}$ University of Wuerzburg, Germany.

* Thorsten Hanke, Efstratios I. Charitos, and Ulrich Stierle contributed equally to the article.

Received for publication March 27, 2008; revisions received June 17, 2008; accepted for publication Aug 5, 2008.

Address for reprints: Hans-H. Sievers, MD, Clinic of Cardiac and Thoracic Vascular Surgery, University of Luebeck, Luebeck, Germany, Ratzeburger Allee 160, 23538

Luebeck, Germany (E-mail: h.sievers@herzchirurgie-luebeck.de).

J Thorac Cardiovasc Surg 2009;137:314-9

$0022-5223 / \$ 36.00$

Copyright (c) 2009 by The American Association for Thoracic Surgery doi:10.1016/j.jtcvs.2008.08.006 root and valve function completely, ${ }^{5,6}$ rendering the durability of the repair questionable. Longer-term follow-up, especially regarding aortic valve function over time, is mandatory for further judgment of the different methods. In an attempt to identify factors influencing the aortic valve function over time in the 2 basic techniques, we analyzed our results up to 12 years postoperatively using a novel hierarchic statistical model for longitudinal outcome analysis, which is considered to be most appropriate for this purpose. ${ }^{7}$ Clinical outcomes regarding the mortality and morbidity of this patient group have been reported in detail. ${ }^{8}$

\section{PATIENTS AND METHODS}

Patients' demographics and clinical and operative profiles are listed in Table 1. Patients' preoperative, perioperative, and follow-up data were collected prospectively in our Aortic Surgery Database. The Ethics Committee of the Medical Faculty of the University of Luebeck approved the data collection within the project and waived the need for patient consent.

When initially collecting our data, we were tempted to exclude patients with acute type A aortic dissection from this analysis because they require surgery on an emergency basis, may present with an increased number of risk factors, require modification and often individualization of surgical technique, and often account for significant postoperative morbidity and mortality. However, for 2 separate reasons we believe that such a decision would be unfair: First, acute type A aortic dissection is not a contraindication for aortic valve-sparing procedures. It is obvious that the aortic valve cannot be spared in all cases; however, we and others believe that a patient's native valve should be preserved whenever possible..$^{9-11}$ Second, as presented below, the preoperative presence of type A acute aortic dissection had no effect on postoperative aortic valve function. 


\section{Abbreviation and Acronym \\ $\mathrm{AR}=$ aortic regurgitation}

\section{Operative Technique}

Standard cardiopulmonary bypass was initiated with a membrane oxygenator (Hollow Fiber Oxygenator, Spiral Gold, Baxter, Puerto Rico) with cold antegrade crystalloid or blood cardioplegia for myocardial protection. Profound hypothermia $\left(15^{\circ} \mathrm{C}-18^{\circ} \mathrm{C}\right)$ and cold antegrade cerebral perfusion were used in cases requiring circulatory arrest.

When the cusps appeared intraoperatively, to be macroscopically intact, without calcifications, thickening, or fenestrations, preference was given to spare the aortic valve, including the bicuspid valves. The choice of valvepreserving technique was merely surgeon related, with the Yacoub technique used more often initially.

The surgical technique of group Y (remodeling technique) has been described in detail. ${ }^{1,6}$ Briefly, the sinuses of Valsalva and the ascending aorta were excised, leaving a rim of $4 \mathrm{~mm}$ attached to the aortic annulus. A vascular Dacron graft was trimmed to produce separate tongue-shaped extensions for replacement of the excised sinuses. These tongues were sutured to the aortic annulus using continuous 4-0 Prolene. Coronary ostia were reimplanted into the graft using the button technique. The detailed surgical technique of group $\mathrm{D}$ (reimplantation technique) has been described in detail. $^{2,12,13}$ In brief, the aortic root was dissected as proximal as possible. Multiple interrupted horizontal 2-0 Teflon felt pledgeted mattress sutures served for fixing a prosthetic tube in the subannular position followed by implantation of the valve into the prosthesis (Hemashield Gold; Meadox Medicals, Oakland, NY). The commissures were also secured with pledget U stitches. The coronary ostia were reimplanted into the graft in the same fashion as in group Y. Graft size was estimated according to the distance between the straightened commissures that provided a macroscopically appropriate leaflet coaptation after the excision of the native aortic sinuses. After completion of root reconstruction, the valve anatomy was finally inspected. A prolapse of $1(n=26)$ or $2(n=3)$ cusps were observed in some patients and corrected with a central plication at the free edge of the cusp using 5-0 Prolene suture with pericardial pledgets. In 1 patient, a continuous polytetrafluoroethylene (Gore-Tex, WL Gore and Associates Inc, Flagstaff, Ariz) 6-0 suture at the free edge was used to correct the prolapse.

\section{Echocardiographic Follow-up}

Follow-up investigations in all survivors were scheduled at discharge and on a yearly basis thereafter. Data were acquired in our outpatient clinic or by the referring cardiologist. The mean duration of the echocardiographic follow-up was $3.09 \pm 2.92$ years (median 2.33 years, range $0.1-12.1$ years). Total echocardiographic follow-up was 560 patient-years. Completeness of echocardiographic follow-up with qualitatively good and complete serial echocardiographic assessment was $95.3 \%$ (total number of examinations 654 , mean $3.6 \pm 2.0$, range $2-13$ measurements per patient).

\section{Echocardiographic Measurements}

Aortic regurgitation (AR) was assessed by multiple techniques by the parasternal long-axis and apical 5-chamber views (Sonos 2500 or 5500 system, Philips Medical Systems, Best, The Netherlands; $2.5 \mathrm{MHz}$ ultrasound transducer). Pulsed-wave Doppler and color flow Doppler imaging were used for mapping the left ventricular outflow tract, including determination of the ratio of jet height to left ventricular outflow tract height. Continuous Doppler imaging was applied to measure the deceleration slope and pressure halftime of the autograft regurgitation jet. AR was assessed by color-flow Doppler techniques according to the ratio of jet height/left ventricular outflow tract height as described by Perry and colleagues, ${ }^{14}$ with a ratio of $1 \%$ to $24 \%$ (grade I), $25 \%$ to $46 \%$ (grade II), $47 \%$ to $64 \%$ (grade III), and more
TABLE 1. Preoperative and intraoperative data of patients undergoing aortic valve-sparing procedures

\begin{tabular}{lccc}
\hline & Remodeling & Reimplantation & $\boldsymbol{P}$ value \\
\hline & $\mathrm{n}=108$ & $\mathrm{n}=83$ & \\
Male & $63 \%$ & $76 \%$ & .08 \\
Mean age (y) & $55.9 \pm 14.3$ & $49.2 \pm 16.9$ & .007 \\
Ascending aneurysm & $73 \%$ & $53 \%$ & .007 \\
Aneurysm diameter (mm) & $60 \pm 13$ & $59 \pm 12$ & .59 \\
Type A dissection & $29 \%$ & $42 \%$ & .09 \\
Marfan syndrome & $13 \%$ & $20 \%$ & .27 \\
Bicuspid aortic valve & $14 \%$ & $11 \%$ & .69 \\
AR $\geq$ grade II & $43 \%$ & $59 \%$ & .04 \\
Previous cardiac operation & $3 \%$ & $4 \%$ & .98 \\
CPB time (min) & $185.2 \pm 44.7$ & $221.2 \pm 59.8$ & $<.001$ \\
Aortic crossclamp time (min) & $138 \pm 39$ & $165 \pm 49$ & $<.001$ \\
Open distal anastomosis & $65 \%$ & $68 \%$ & .78 \\
$\quad$ With partial arch & $33 \%$ & $26 \%$ & .38 \\
$\quad$ With total arch & $3 \%$ & $8 \%$ & .22 \\
With concomitant procedures & $29 \%$ & $23 \%$ & .44 \\
Mean size of graft (mm) & $28.2 \pm 1.7$ & $28.7 \pm 1.8$ & .05 \\
Additional cusp intervention & $13 \%$ & $19 \%$ & .35 \\
Additional annulus intervention & $20 \%$ & 0 & $<.001$ \\
GRF glue used & $13 \%$ & $19 \%$ & .35 \\
\hline AR A A & & & \\
\hline
\end{tabular}

$A R$, Aortic regurgitation; $C P B$, cardiopulmonary bypass; $S D$, standard deviation; $G R F$, gelatine-resorcine-formol. Values are expressed as mean $\pm \mathrm{SD}$ or percentage of patients.

than $65 \%$ (grade IV). Trace (trivial) aortic insufficiency, defined as a tiny regurgitation jet in early diastole near the detection limit, was included in the analysis as grade 0.5 .

\section{Measurement of the Preoperative Aortic Valve Annulus Diameter}

Measurements of the preoperative aortic annulus diameters were performed by using the Quantcor QCA software (Pie Medical Imaging, Maastricht, The Netherlands). Calibration was achieved using the size of the diagnostic catheter as reference. During left ventricular angiography and aortography, aortic annulus diameters were assessed by measuring the distance between the nadirs of the aortic root sinuses in mid-diastole. Three measurements were averaged for final estimation.

\section{Statistical Analyses}

Comparison between the groups was performed using the Mann-Whitney $U$ test, chi-square test, and Fisher's exact test, where appropriate. Actuarial estimates of overall survival and freedom from aortic valve reoperation were accomplished with the Kaplan-Meier methods.

To study the aortic valve function (regurgitation) and aortic root dimensions with time, a multilevel modeling technique was used as recently proposed $^{15}$ and endorsed by the latest guidelines for reporting outcome after valve interventions. ${ }^{7}$ Statistical analysis of initial fitting and the influence of covariables was performed. A linear model with random coefficients was chosen to model AR with time according to the following formula:

$$
\begin{aligned}
\mathrm{AR} \text { grade }(\text { time })= & (\text { initial AR grade } \pm \text { standard error }) \\
& +(\text { annual AR increase } \pm \text { standard error }) \\
& \times \text { time }(\mathrm{y}) .
\end{aligned}
$$

The echocardiographic data of 2 or more echocardiographic measurements per patient were analyzed with a hierarchic multilevel linear model 
(MLWin 2.0, Centre for Multilevel Modeling, London, UK). This model provides a linear regression line with an intercept and slope for each individual patient. The intercept (initial AR grade \pm standard error) corresponds to the notional value of AR at the time of surgery, whereas the slope (annual increase in $\mathrm{AR} \pm$ standard error) represents the annual progression of it. ${ }^{15}$ All authors had access to the patients' data and take full responsibility for their integrity.

\section{RESULTS}

The results regarding valve-related morbidity and mortality have been presented in detail. ${ }^{8}$

\section{Echocardiographic Data}

Descriptive results of the most recent follow-up visit are displayed in Table 2.

\section{Aortic Regurgitation with Time}

The mean initial AR grade was estimated to be 0.426 , with an average increase of $0.082 \mathrm{AR}$ grades per year. Thus, after 10 years, the mean AR grade was estimated to increase by 0.82 AR grades.

Patients who underwent the remodeling technique had a significantly greater initial AR grade (group Y: $0.492 \pm$ 0.042 vs group D: $0.336 \pm 0.048 ; P=.013)$ and greater annual increase of AR (group Y: $0.099 \pm 0.019$ vs group D: $0.041 \pm 0.025 ; P=.061$ ) (Figure 1 ). This translates to an estimated increase of 1.0 AR grades in the remodeling group and $0.4 \mathrm{AR}$ grades in the reimplantation group within 10 years postoperatively. Of the various analyzed determinants of AR over time, only Marfan disease, cusp intervention, and preoperative aortic annulus diameter showed a significant association with the development of postoperative AR. Of note, the presence of acute type A aortic dissection did not significantly influence the longitudinal performance of aortic valve function in either technique.

TABLE 2. Echocardiographic data of patients at the time of the most recent follow-up examination

\begin{tabular}{lccc}
\hline \multicolumn{2}{c}{ Remodeling } & Reimplantation & P value \\
\hline Aortic root dimensions (mm) & & \\
$\quad$ Annulus & $23 \pm 4$ & $22 \pm 3$ & .13 \\
Mid sinus & $30 \pm 4$ & $26 \pm 4$ & $<.001$ \\
STJ & $25 \pm 3$ & $25 \pm 4$ & 1.0 \\
Ascending aorta & $30 \pm 4$ & $29 \pm 3$ & .13 \\
Aortic valve area $\left(\mathrm{cm}^{2}\right)$ & $3.0 \pm 1.1$ & $2.2 \pm 0.8$ & $<.001$ \\
Pressure gradient LVOT (mm Hg) & & .003 \\
Maximal & $9.3 \pm 1.1$ & $12.6 \pm 9.5$ & .19 \\
Mean & $4.9 \pm 4.6$ & $6.0 \pm 4.6$ & .003 \\
Aortic valve regurgitation $(\mathrm{n}, \%)$ & & .37 \\
None & $15(20 \%)$ & $23(47 \%)$ & .23 \\
Trivial & $23(31 \%)$ & $11(22 \%)$ & .42 \\
Mild & $28(37 \%)$ & $12(25 \%)$ & \\
$\geq$ grade II & $9(12 \%)$ & $4(6 \%)$ & \\
\hline STJ Sinotubular junction; $L V O T$, left ventricular outflow tract. Values are expressed \\
as mean \pm SD, absolute numbers or percentage of patients.
\end{tabular}

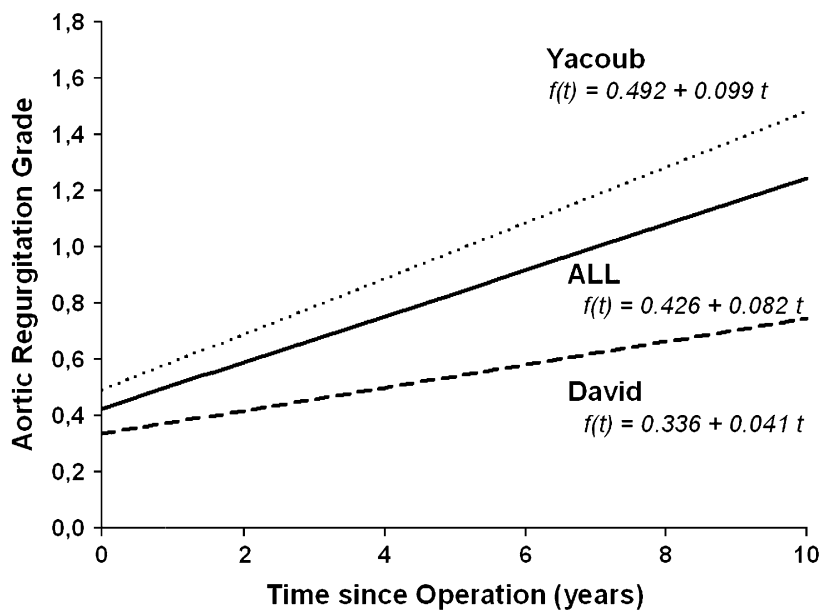

FIGURE 1. Estimation of AR with time in patients treated with the Yacoub and David technique. There is significant evidence that the mean intercept (AR at time 0$)$ is higher for the Yacoub technique $(P=.013)$, but there is no significant difference regarding the annual progression rate of AR for both techniques $(P=.061)$.

The mean intercept of AR grade (AR grade early postoperative) in Marfan disease was higher with the remodeling technique ( $P=.049$; Figure 2 ). This translates to an initial AR grade of 0.56 and an annual increase of 0.132 grades. Thus, after 10 years, the AR grade was estimated to increase by $1.32 \mathrm{AR}$ grades in the remodeling group and by $0.75 \mathrm{AR}$ grades in the reimplantation group. Although there is no evidence of a significant difference of the slope between both surgical techniques, a sustained gap between both groups is remarkable (Figures 2 and 3 ). To determine the effect of a potential "learning curve," aortic valve function after both techniques was analyzed, this time allowing for

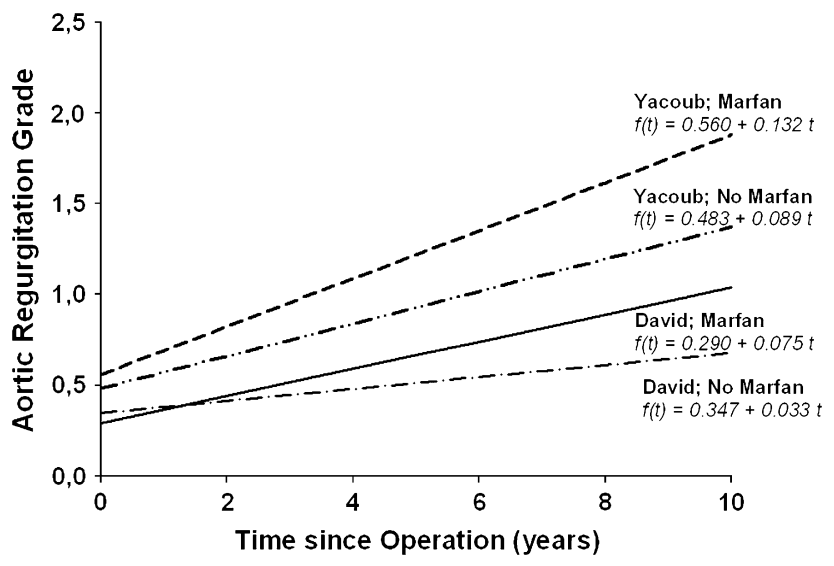

FIGURE 2. Estimation of AR over time in patients with or without Marfan disease allowing for the surgical technique. The difference in mean intercept ( $P=.049)$ between the David and Yacoub methods is marginally significant. The difference of the mean annual progression rate of AR is not significant between the groups $(P=.10)$. The higher intercept plus the marginally higher slope for Yacoub's method mean that a sustained gap between the methods is present. 


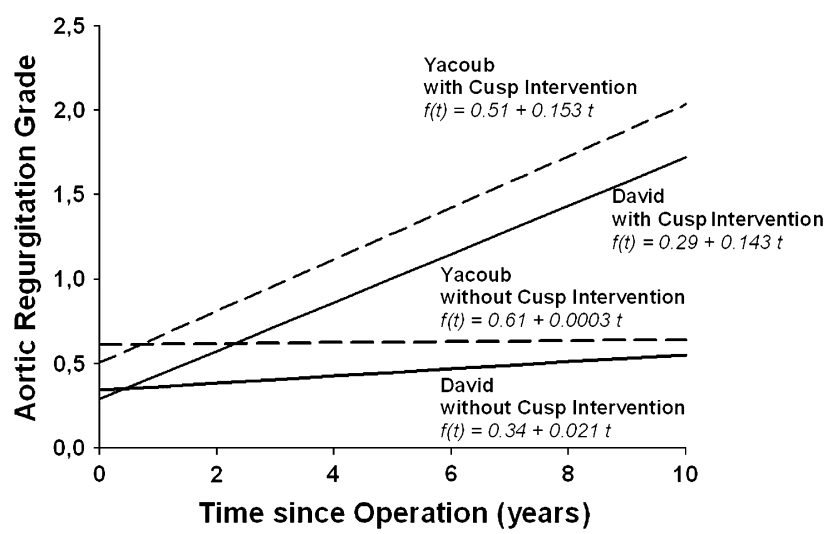

FIGURE 3. Estimation of AR over time in patients with or without cusp interventions, predominantly as a central plication procedure, allowing for the surgical technique. There is no evidence that the mean intercepts differ depending on whether there were cusp interventions or not $(P=.38)$, but there was significant evidence of an increase in the annual progression rate of AR with cusp intervention $(P<.0001)$ for both surgical techniques.

year of surgery. No statistically significant interference could be observed between the year of surgery and the time course of postoperative aortic valve function.

The initial AR grade was comparable in patients with and without cusp interventions $(0.40 \pm 0.08$ vs $0.52 \pm 0.04 ; P=$ $.19)$, but the annual progression rate was significantly higher among patients with cusp interventions $(0.003 \pm 0.018$ vs $0.096 \pm 0.017 ; P<.0001$, Figure 3 ). The differences between intercepts were similar for the 2 types of operation, as were the differences between slopes (interaction $P=.85$ ).

In patients who underwent the remodeling technique, larger preoperative aortic annulus diameters were significantly associated with greater long-term AR. This is in contrast with the reimplantation subgroup, in whom the development of AR over time was more pronounced when the aortic annulus diameter was smaller at the time of surgery (Figure 4, $A$ and $B$ ).

\section{DISCUSSION}

Both techniques of valve-sparing operations have been shown to adequately preserve aortic valve function in patients with aneurysms of the ascending aorta or root, ${ }^{2,9,13,16-18}$ type A aortic dissection, ${ }^{19,20}$ and Marfan syndrome. ${ }^{4,21,22}$

In vivo and in vitro, both techniques and their modifications preserve aortic root distensibility and valve performance to different extents, ${ }^{3,5}$ although none of the techniques completely reproduce the normal aortic valve and root dynamics. ${ }^{5}$ The distensibility of the root is restricted or completely abolished with these techniques, and the bending deformation of the cusps itself is increased. It is frequently observed that the cusps collide with the prosthetic wall during systole. ${ }^{5}$ These limitations render the durability of repair in terms of aortic valve function at the focus of research.

\section{The Problem of Serial Assessment of Aortic Valve Function with Time}

In most studies, serial echocardiographic examinations are reported as a tool of follow-up examination and determination of valve function. The analysis of these serial echocardiographic data is impaired by several factors. Echocardiographic information is obtained at different time points and intervals, appointments may be missed, and valve function is often variable with time. In addition, there is interobserver and intraobserver variability, and the equipment settings of the echocardiography device also influence the measurements. We believe that although the Kaplan-Meier survival function is commonly used for the analysis of terminal (death) or binary (reoperation) events, it is inappropriate for the analysis of events showing significant temporal
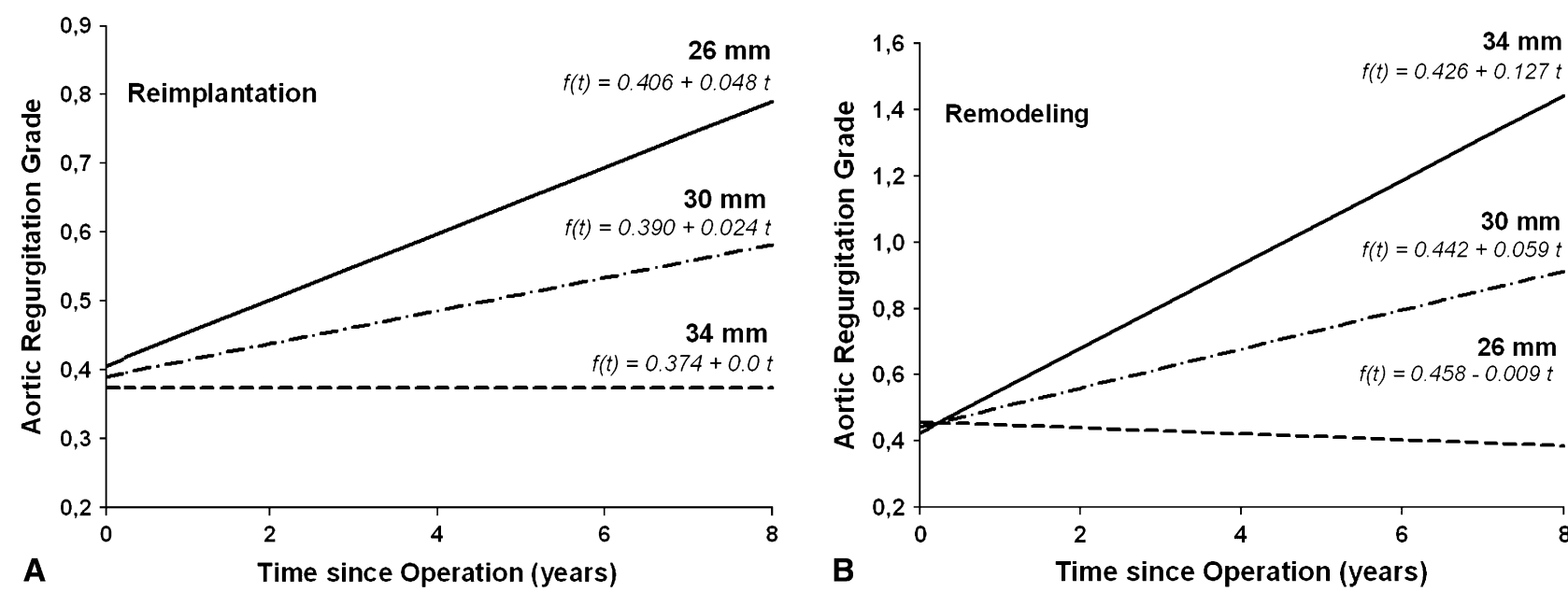

FIGURE 4. Multilevel modeling of the association of preoperative aortic annulus diameter and AR grade with time in patients treated with the reimplantation (A) and remodeling (B) techniques. With increasing diameters of the aortic annulus, aortic valve incompetence is pronounced in patients treated with the remodeling technique, whereas smaller diameters and reimplantation technique are associated with deterioration of valve function. 
variance, such as autograft function (degree of AR, freedom from a prespecified grade of AR), an opinion shared by others ${ }^{15}$ and endorsed in the latest guidelines for reporting outcome after valve interventions. ${ }^{7}$ Such analysis may introduce significant bias and aliasing that can significantly distort results and alter conclusions. Despite the simplicity of the Kaplan-Meier method, we have meticulously avoided expressing our results on aortic valve function with this method because with all these meaningful limiting factors, the conventional Kaplan-Meier method is inappropriate. The multilevel modeling technique used in this study adequately deals with these issues and allows multivariable risk factor analysis of the initial AR grade and annual progression rate. This technique is the most appropriate to achieve more insight into the aortic valve over time in valve-sparing operations.

\section{Aortic Valve Function Over Time}

The AR grade early after operation was higher in the remodeling group. An annual increase of AR was detected in both techniques, with a trend toward higher values in the remodeling group, reflected by the higher number of patients who required a reoperation because of AR. In other cases, progressive dilatation of the aortic annulus led to cusp displacement out of the coaptation area. In general, the present observations were in accordance with results of other groups. ${ }^{9,10,23,24}$ In addition, this study serves to identify factors that were associated with increased AR over time, especially Marfan syndrome, cusp intervention, and preoperative annulus diameter.

\section{Marfan Syndrome}

There are accumulating data that Marfan syndrome represents a risk factor for reoperation on the initially spared valve. ${ }^{4,25}$ Several factors and their interaction may contribute to this complex issue with involvement of the cusp tissue itself and the aortic annulus. In patients undergoing the remodeling technique, a more substantial increase in AR was detected, resulting in an estimated increase of 1.32 in AR grade after 10 years (vs increase of 0.75 in AR grade in the reimplantation group). Because AR is usually well tolerated, reported rates of reoperations may underestimate failure rates of the spared aortic valve. As a consequence, the remodeling technique in patients with Marfan syndrome is now used in our center more restrictively, and a close follow-up must be ensured. Our observations are in accordance with the findings recently published by David and colleagues. ${ }^{9}$

\section{Cusp Intervention}

An important issue regarding the valve-sparing operations is whether and how concomitant cusp interventions influence the long-term aortic valve function. Several years ago, numerous pathologies (low cusp coaptation area, cusp prolapse, or stress fenestrations in the commissural areas) have been regarded as contraindications to aortic valve- sparing operations. Currently, in experienced hands, a more liberal approach is accepted with good functional results in the mid-term. ${ }^{26}$ This is in partial contrast with our findings in both valve-sparing techniques. AR was estimated to increase substantially by $1.5 \mathrm{AR}$ grade after 10 years if cusp interventions, mostly a plication of the free edge of 1 or 2 cusps, were performed. Several factors may play an important role: unsuitable valve for cusp interventions, secondary fibrotic retraction of the cusp margins after interventions in the long-term, or improper surgical techniques. In addition, tissue properties of the aortic valve cusps (bicuspid with a more rigid cusp tissue vs tricuspid with thin and vulnerable tissue) may play an important role. Because the immediate results seem favorable, there may be time-dependent factors that can adversely affect cusp function after the initial intervention. Nevertheless, these results indicate that exact root reconstruction without cusp intervention is advisable. Improved techniques for cusp intervention, such as free-edge resuspension with polytetrafluoroethylene (GoreTex) continuous sutures ${ }^{27}$ and proper selection of reparability, could further improve results. However, none of the patients who underwent reoperation had leaflet repair, which supports our opinion that leaflet repair per se does not necessarily lead to reoperation but seems to have an increased development of AR over time. Our data were not sufficient to determine whether the observed adverse outcomes after concomitant cusp interventions could be attributed to unsuitable valve pathology or improper technique.

\section{Preoperative Aortic Annulus Diameter}

A larger preoperative annulus seems to favor later AR in group Y. This has some plausibility because the annulus diameter clearly affects cusp coaptation. Increasing diameters, as observed in this study, may result in reduction of the coaptation area. We prefer the David operation in patients with preoperative annulus diameters exceeding 28 to $30 \mathrm{~mm}$, which is in accordance with other authors. ${ }^{17}$ It is difficult to interpret why smaller preoperative aortic diameters facilitate the development of AR in the reimplantation technique. Perhaps the cusps are smaller in roots with small preoperative annulus diameters and more susceptible for later development of AR, for yet unknown reasons. Of note, the transvalvular pressure gradients were significantly higher in the reimplantation group. This may cause a more turbulent flow with cusp tissue injuries over time and consequently an accelerated cusp failure. Reimplantation of the valve into a prosthetic tube with a fixed diameter leads to a reduction of the functional orifice area of the left ventricular outflow, which is relatively more pronounced in smaller annular diameters and as such may augment this mechanism.

\section{Study Limitations}

The limitations of this study are mainly due to its nonrandomized design. However, because the differences in 
both groups are small, a prospective randomized multicenter study, which would be desirable for an objective comparison of both techniques, would require a large number of patients. In addition, there is a considerable number of different modifications of both techniques, rendering a standard surgical protocol difficult to follow. The mean follow-up time is limited, and the number of major cardiac events (eg, reoperation) is small and mainly the result of primary technical faults within the first years. A main limitation of the study is the evolution of the surgical approach within the last decade. Additional interventions were introduced and applied in different root pathologies, and personal/institutional preferences changed over time. Long-term follow-up is necessary to evaluate multivariable effects on clinically important subsets.

\section{CONCLUSIONS}

This study, using a novel statistical approach, provides some evidence that patients with Marfan syndrome and aortic roots with large preoperative annulus diameters may benefit from the reimplantation technique, and that those with small preoperative annulus diameters may benefit from the remodeling technique using a diameter of 28 to $30 \mathrm{~mm}$ as a reasonable cutoff value. Central plication of prolapsing cusps is disadvantageous for aortic valve function over time.

The authors gratefully acknowledge the excellent technical assistance of P. Lingens, I. Beyer, and K. Meyer.

\section{References}

1. Fagan A, Yacoub MH, Pillai R, Radley-Smith R. Dacron replacement of the ascending aorta and sinuses with resuspension of the aortic valve and reimplantation of the coronary arteries: a new method for treatment of aneurismal or acute dissection of the aortic root. Proceedings of the Joint International Cardiovascular and Thoracic Surgical Conference, Stockholm [abstract]. Scand J Cardiothorac Surg. 1982.

2. David TE, Feindel CM. An aortic valve-sparing operation for patients with aortic incompetence and aneurysm of the ascending aorta. J Thorac Cardiovasc Surg. 1992;103:617-21

3. De Paulis R, De Matteis GM, Nardi P, Scaffa R, Buratta MM, Chiariello L. Opening and closing characteristics of the aortic valve after valve-sparing procedures using a new aortic root conduit. Ann Thorac Surg. 2001;72:487-94.

4. Miller DC. Valve-sparing aortic root replacement in patients with the Marfan syndrome. J Thorac Cardiovasc Surg. 2003;125:773-8.

5. Erasmi A, Sievers HH, Scharfschwerdt M, Eckel T, Misfeld M. In vitro hydrodynamics, cusp-bending deformation, and root distensibility for different types of aortic valve-sparing operations: remodeling, sinus prosthesis, and reimplantation. J Thorac Cardiovasc Surg. 2005;130:1044-9.

6. Sarsam MA, Yacoub M. Remodeling of the aortic valve anulus. J Thorac Cardiovasc Surg. 1993;105:435-8.
7. Akins CW, Miller DC, Turina MI, Kouchoukos NT, Blackstone EH, Grunkemeier GL, et al. Guidelines for reporting mortality and morbidity after cardiac valve interventions. J Thorac Cardiovasc Surg. 2008;135:732-8.

8. Erasmi AW, Sievers HH, Bechtel JF, Hanke T, Stierle U, Misfeld M. Remodeling or reimplantation for valve-sparing aortic root surgery? Ann Thorac Surg. 2007; 83:S752-6.

9. David TE, Feindel CM, Webb GD, Colman JM, Armstrong S, Maganti M. Longterm results of aortic valve-sparing operations for aortic root aneurysm. J Thorac Cardiovasc Surg. 2006;132:347-54

10. Kallenbach K, Karck M, Pak D, Salcher R, Khaladj N, Leyh R, et al. Decade of aortic valve sparing reimplantation: are we pushing the limits too far? Circulation. 2005;112:I253-9.

11. Kallenbach K, Leyh RG, Salcher R, Karck M, Hagl C, Haverich A. Acute aortic dissection versus aortic root aneurysm: comparison of indications for valve sparing aortic root reconstruction. Eur J Cardiothorac Surg. 2004;25:663-70.

12. David TE. Sizing and tailoring the Dacron graft for reimplantation of the aortic valve. J Thorac Cardiovasc Surg. 2005;130:243-4.

13. David TE, Ivanov J, Armstrong S, Feindel CM, Webb GD. Aortic valve-sparing operations in patients with aneurysms of the aortic root or ascending aorta. Ann Thorac Surg. 2002;74:S1758-61.

14. Perry GJ, Helmcke F, Nanda NC, Byard C, Soto B. Evaluation of aortic insufficiency by Doppler color flow mapping. J Am Coll Cardiol. 1987;9:952-9.

15. Takkenberg JJ, van Herwerden LA, Galema TW, Bekkers JA, KleyburgLinkers VE, Eijkemans MJ, et al. Serial echocardiographic assessment of neoaortic regurgitation and root dimensions after the modified Ross procedure. J Heart Valve Dis. 2006;15:100-6.

16. David TE, Armstrong S, Ivanov J, Feindel CM, Omran A, Webb G. Results of aortic valve-sparing operations. J Thorac Cardiovasc Surg. 2001;122:39-46.

17. Schafers H, Fries R, Langer F, Nikoloudakis N, Graeter T, Grundmann U. Valvepreserving replacement of the ascending aorta: remodeling versus reimplantation. J Thorac Cardiovasc Surg. 1998;116:990-6.

18. Yacoub MH, Gehle P, Chandrasekaran V, Birks EJ, Child A, Radley-Smith R Late results of a valve-preserving operation in patients with aneurysms of the ascending aorta and root. J Thorac Cardiovasc Surg. 1998;115:1080-90.

19. Graeter TP, Langer F, Nikoloudakis N, Aicher D, Schafers HJ. Valve-preserving operation in acute aortic dissection type A. Ann Thorac Surg. 2000;70:1460-5.

20. Leyh RG, Schmidtke C, Bartels C, Sievers HH. Valve-sparing aortic root replacement (remodeling/reimplantation) in acute type A dissection. Ann Thorac Surg. 2000;70:21-4.

21. de Oliveira NC, David TE, Ivanov J, Armstrong S, Eriksson MJ, Rakowski H, et al. Results of surgery for aortic root aneurysm in patients with Marfan syndrome. J Thorac Cardiovasc Surg. 2003;125:789-96.

22. Karck M, Kallenbach K, Hagl C, Rhein C, Leyh R, Haverich A. Aortic root surgery in Marfan syndrome: comparison of aortic valve-sparing reimplantation versus composite grafting. J Thorac Cardiovasc Surg. 2004;127:391-8.

23. Cattaneo SM, Bethea BT, Alejo DE, Spevak PJ, Clauss SB, Dietz HC, et al. Surgery for aortic root aneurysm in children: a 21 -year experience in 50 patients. Ann Thorac Surg. 2004;77:168-76.

24. Miller DC. Valve-sparing aortic root replacement: current state of the art and where are we headed? Ann Thorac Surg. 2007;83:S736-9.

25. Kallenbach K, Baraki H, Khaladj N, Kamiya H, Hagl C, Haverich A, et al. Aortic valve-sparing operation in Marfan syndrome: what do we know after a decade? Ann Thorac Surg. 2007;83:S764-8.

26. David TE, Feindel CM, Webb GD, Colman JM, Armstrong S, Maganti M. Aortic valve preservation in patients with aortic root aneurysm: results of the reimplantation technique. Ann Thorac Surg. 2007;83:S732-5.

27. Jeanmart H, de Kerchove L, Glineur D, Goffinet JM, Rougui I, Van Dyck M, et al. Aortic valve repair: the functional approach to leaflet prolapse and valve-sparing surgery. Ann Thorac Surg. 2007;83:S746-51. 